\title{
Demand Response Implementation in an Optimization Based SCADA Model Under Real-Time Pricing Schemes
}

\author{
Mahsa Khorram, Pedro Faria, Omid Abrishambaf, Zita Vale \\ GECAD - Research Group on Intelligent Engineering and Computing for Advanced Innovathon \\ and Development, Institute of Engineering, Polytechnic of Porto (ISEP/IPP), Portiti \\ $\{$ makgh, pnfar, ombaf, zav\}@isep.ipp.pt
}

\begin{abstract}
Advancement of renewable energy resources, develefojimetingt of smart. grids, and the effectiveness of demand response programs, cai be coujsiderêtas solutions to deal with the rising of energy consumption. Howevertiots no benefit if the consumers do not have enough automatiofitinfrastrature to use the facilities. Since the entire kinds of buildings have a giassive portion electricity usage, equipping them with optimization-based. system

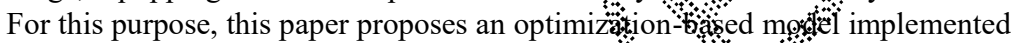
in a Supervisory Control and Data Acquisition, optimization model is based on power retetetion of conditioners and lighting systems of an office building with respect to the pifse-based demand response programs, such as real-time pricing. The proposed system utilizes several agents associated with the different distribüted based controller devices in order to per-

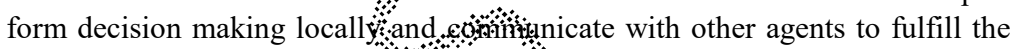
overall system's goal. In.the câse study of the paper, the proposed system is used

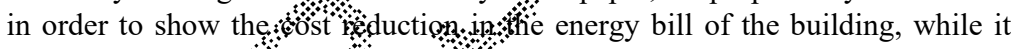
respects the user pieferences and comfort level.
\end{abstract}

\section{Introdüction}

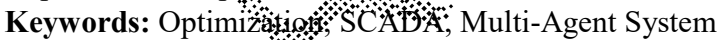

唡

Currently owerowistribution networks are being updated and move towards the smartigrids a s. shantion ânzeneration [2]. On the other hand, the daily increment of electricity usage $\therefore$ fored the network operators to reduce the method of generation by fossil fuels [3], and .. move (PV) systems and wind turbines [4]. A significant part of electricity consumption is
allocated to commercial buildings, especially office buildings [5]. In this context, Air .

The present work was done and funded in the scope of the following projects: H2020 DREAMGO Project (Marie Sklodowska-Curie grant agreement No 641794); Project GREEDI (ANI|P2020 17822); and UID/EEA/00760/2013 funded by FEDER Funds through COMPETE program and by National Funds through FCT. 
Conditioners (ACs) have great contribution on the consumption of these kinds of buildings [6]. Demand Response (DR) programs are considered as a solution for managing the consumption of the demand side [7].

DR program is referred to modification of consumption pattern by the end-users in response to the incentives payment by the DR managing entities, which is due to any economic or technical reasons [8]. Real-Time Pricing (RTP) is an example of price based DR programs, which is applied in day-ahead economic scheduling [9]. In order to implement these programs, the end-users should be equipped with several autoination infrastructures in order to be able to perform these programs [10]. Supow Control And Data Acquisition (SCADA) system plays a key role in DR ingalementation, since it offers various advantages in order to have automatic load control.in dift: ferent types of buildings [11].

Multi-Agent System (MAS) is an essential tool for SCADA systitis for contrôtiting strategies and exchanging system status [12]. In fact, MAS bäsed $\$$ CAD\% would be able to perform complex optimization algorithm, and simultantieovisty, manage the controllable loads connected to SCADA system [1,3]: Flexibuity and adaptability are two main capabilities that a MAS offers [14].

This paper represents an optimization algoritam moptementes in a MAS based SCADA model for an office building. The proposed algowithnminanages the consumption of the building under RTP tariff and manages the contsumption of the ACs and illumination systems of the building based on fefined priorities by the office users. Furthermore, the controlling of the loads is performed through a MAS model, which each agent is associated with partietitatopart of the implemented SCADA system. This enables the model to perform decision agents to fulfill the overall system $\mathrm{s}$ goal.

The rest of the paper orgatized of fortlows. The MAS implemented in SCADA model is described on Section. $\%$ Section 3 represents the proposed optimization algorithm. A case study is reproted in Section 4 , and its results are illustrated in the same section. Section detailsthe conclusions of the work.

\section{Mứtid-Ägent yodel Architecture}

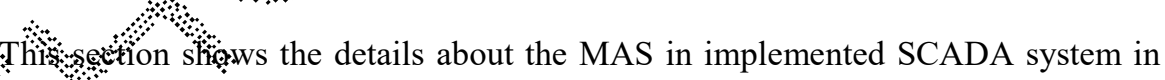
irder to congtrol the consumption of building. The automation infrastructures have been ifiplementedin a part of GECAD research center building, which contains 8 offices, 1

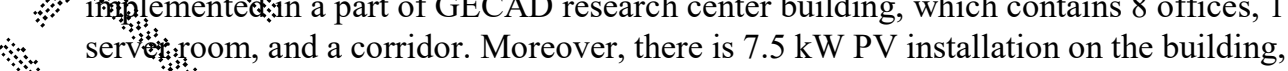

which supplies a part of total consumption. For managing the consumption of building, haree distributed based Programmable Logic Controllers (PLCs) dedicated for a zone iincluding three offices. Therefore, there are three zones somehow each PLC associated with one zone. Moreover, there is a main PLC that is responsible for supervising the other distributed based PLCs. The main controlling panel of the SCADA system including all PLCs is shown on Fig. 1. The controllable loads by the SCADA include lighting systems and ACs, which are controlled by several communication protocols. 
Moreover, the real-time consumption of the building is measured through several energy meters. In this model, there are five main agents that each of which is run by a Raspberry Pi (www.raspberrypi.org). As Fig. 1 illustrates, Agent Z1, Z2, and Z3 are devoted for each zone, where these agents are equipped with a PLC for performing controlling decisions locally.

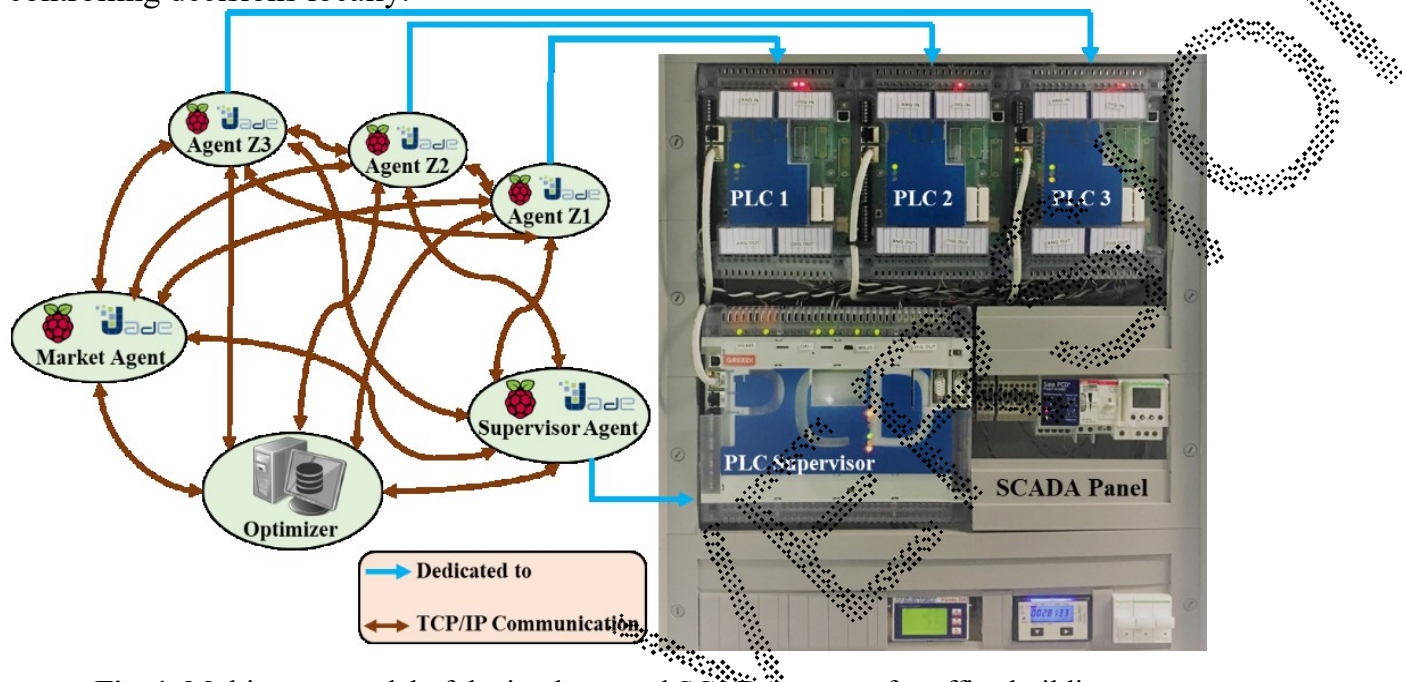

Fig. 1. Multi-agent model of the implemented SCÂ $\mathrm{r}$ - system for office building.

$$
\text { . }
$$

Moreover, Market Agent is resionsible inform the other agents from the real-time electricity price of the market In thin mode the unit called Optimizer is accountable

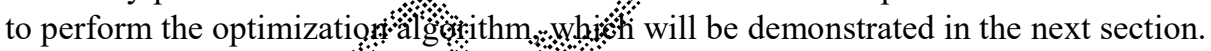
Additionally, the Supery there is any faulty agent, it actonfigures the system. All agents in this system continuously exchanges aressages fô. sharing their latest status through TCP/IP communication. By this way the respons tîne to any changes will be reduced and adaptability of the system.will tures that withe befferediog this MAS.
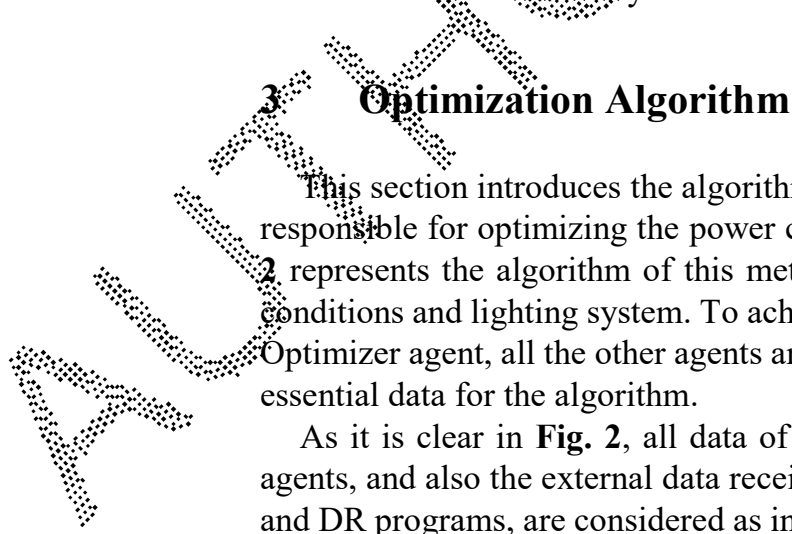

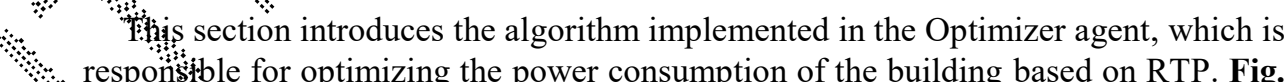
responsiste for optimizing the power consumption of the building based on RTP. Fig.
2. represents the algorithm of this methodology, based on the power reduction of air onditions and lighting system. To achieve the purpose of running this algorithm in the Optimizer agent, all the other agents are obligated to many tasks, such as providing the essential data for the algorithm.

As it is clear in Fig. 2, all data of the building, which are transmitted from other agents, and also the external data received from Market agent, such as electricity price and DR programs, are considered as input data of the algorithm. After definition of the input data, the algorithm performs the decision making for starting optimization. This 
optimization considered as RTP based, since it will be triggered if the electricity prices goes greater than a specific value. In this optimization, comfort level of user is a critical input. For each AC and light, a specific priority value attributed, which determines contribution of each device in optimization. In the User Data inputs, there is an optional rate for the users, which defines the desired rate of power reduction.
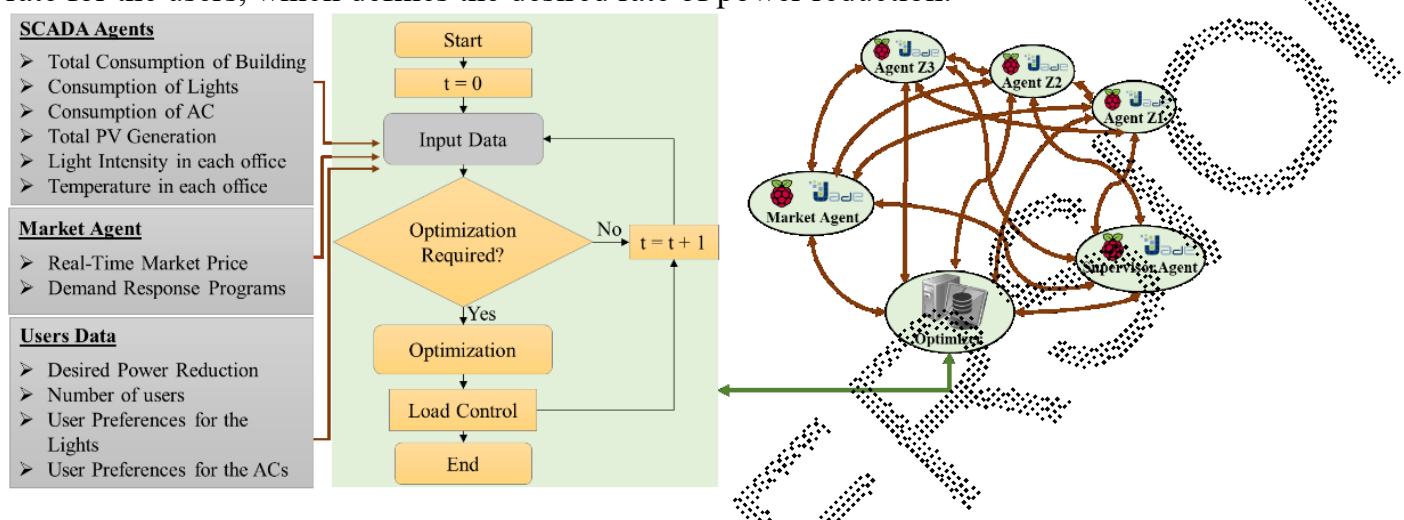

Fig. 2. The procedure of optimi ationtalofithm,

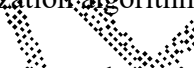

The ACs devices have various priority nembers in each period, since the algorithm should not turn off only specific devices in all pertiods. Also, in the lights, they are not obligated to participate in the optimization in all periơots. This means in certain periods that ACs optimization is not enought to achieve the amount of required reduction of algorithm, lights are as auxiliary fart forthe $\mathrm{ACs}$. For maintaining the comfort of user, the lights optimization also is basece on the अriorities defined by the users. Moreover,

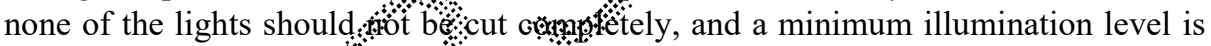
considered for each light:

The proposed methodomoy is modelled as a linear Programming (LP) optimization problem, which «s solved vien.Lp_solve" package of Rstudio ${ }^{\circledR}$ (www.rstudio.com). The main objective function of the optimization algorithm is shown by (1), which aims to minimize the

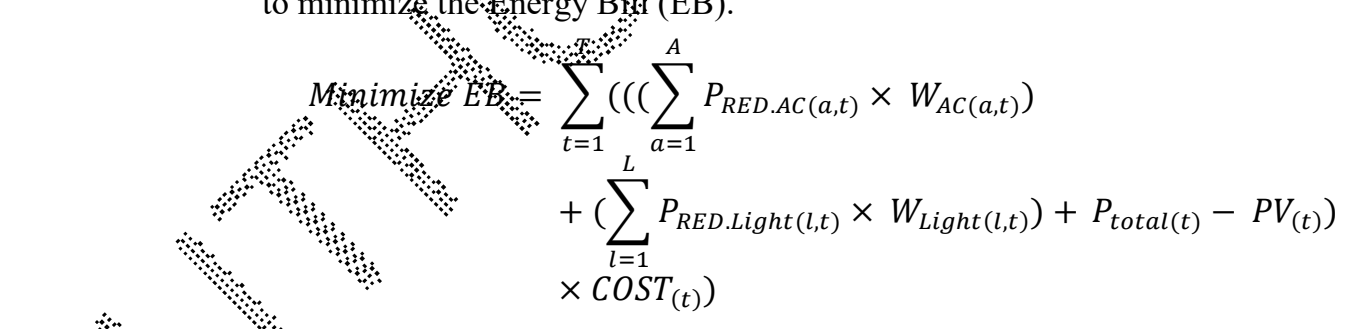

Where $P_{R E D . A C}$ is the power that will be reduced from each AC, and $P_{R E D \text {.Light }}$ is the ate of power that will be reduced from each lights, which are based on the defined input data by users for the rate of desired power reduction. $W_{A C}$ and $W_{\text {Light }}$ are the abbreviation of weight of the priority of the ACs, and the lights respectively. $P_{\text {total }}$ expresses the total power consumption of the building, $P V$ stands for total $\mathrm{PV}$ generation of the building, and COST is the electricity price. $T$ is the maximum number of periods, and finally, $A$ and $L$ are maximum number of ACs and lights, respectively. 
Equation (2) and (3) shows the limitation of priority number, which should be a value between 0 and 1 . Each priority number closer to 0 is the lowest important device for the users and algorithm as well. Equation (4) illustrates the required reduction of the algorithm, which should be decreased to fulfill the goal of the algorithm. Equation (5) shows that the lights will not participate in entire periods of optimization, and they are limited to be reducted only in critical periods.

$$
\begin{gathered}
0 \leq W_{A C(a, t)} \leq 1 \quad \forall 1 \leq t \leq T ; \forall 1 \leq a \leq A \\
0 \leq W_{\text {Light }(l, t)} \leq 1 \quad \forall 1 \leq t \leq T ; \forall 1 \leq l \leq L \\
\sum_{a=1}^{A} P_{R E D . A C(a, t)}+\sum_{l=1}^{L} P_{R E D . L i g h t}(l, t)=R R_{\text {Total }(t)} \\
R R_{\text {Light }(t)}=R R_{\text {Total }(t)}-\sum_{l=0}^{L} P_{R E D . A C(l, t)}^{M A X X}
\end{gathered}
$$

$R R_{\text {Total }}$ is for total Required Reduction, and $P_{R E D E A C}^{M A X}$ is the maximum capacity of ACs for reduction. $R R_{\text {Light }}$ stands for required poikr. reatiction. from lights, which should be a value lower than maximum reductionn câke $\left(P_{R E D \text { Light (t) }}^{M A X}\right)$, as shown on (6). For the limitation 6 powereduction, (7) shows the technical limitation for each light. and (8) show the the discrete control of ACs, which
should be off or on.

\section{Case. Stüdyanî Results}

(3.

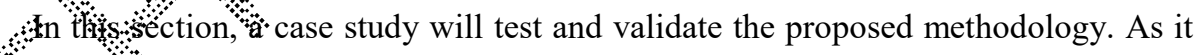
irevioustymentioned, main purpose of this paper is to optimize the building consumptiơf: with taking advantages of MAS in the implemented SCADA system. There are 8

ACs . AC is löcated in the server room that is always turned. The lighting system contains 19 fuorescents lamps that are controlled by SCADA via Digital Addressable Lighting InEirface (DALI). In this case study, it is considered that SCADA model is configured somehow that if the electricity price is greater than $0.08 \mathrm{EUR} / \mathrm{kWh}$ (considered as Base Price), it will perform the optimization algorithm. Also, if the prices increased, the SCADA system specifies more reduction in the optimization algorithm. Fig. 3 illustrates obtained results after and before performing the optimization algorithm for 24 hours (24 periods). 
The consumption and generation curves used in this case study are the real consumption and generation of GECAD building adapted from GECAD database. Moreover, the market prices are for a winter day in 2018 and have been adapted from Portuguese sector of Iberian Electricity Markets (MIBEL - www.omie.es)

As you can see in Fig. 3, the optimization process starts at 9:00 and finishes at 20:00, since the electricity price is higher than Base Price, therefore, the system performs the optimization in order to reduce the energy bill. Furthermore, PV generation profite shown on Fig. 3 is the maximum generation capacity of the system.

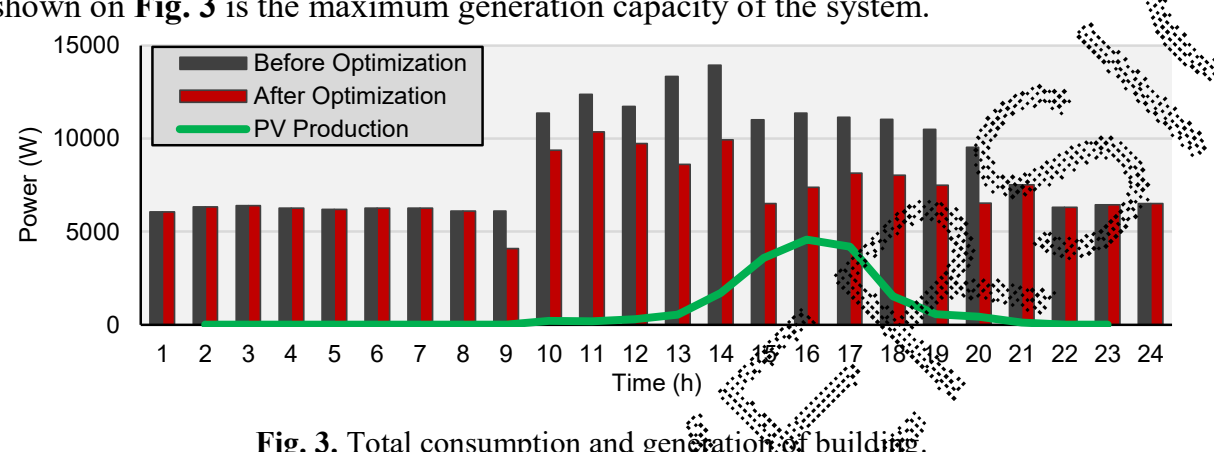

Fig. 3. Total consumption and genation buildiut<smiles>C1#CC2CC12</smiles>

In fact, the power reduction shown on Fig can related only to the ACs reduction, or in some periods can be the cooperation of the lights reduction in order to achieve the desired reduction. Fig:4.illustrates the contribution of ACs, and Fig. 5 demonstrates the contribution of 1 ingting system in the optimization process based on RTP for one day.

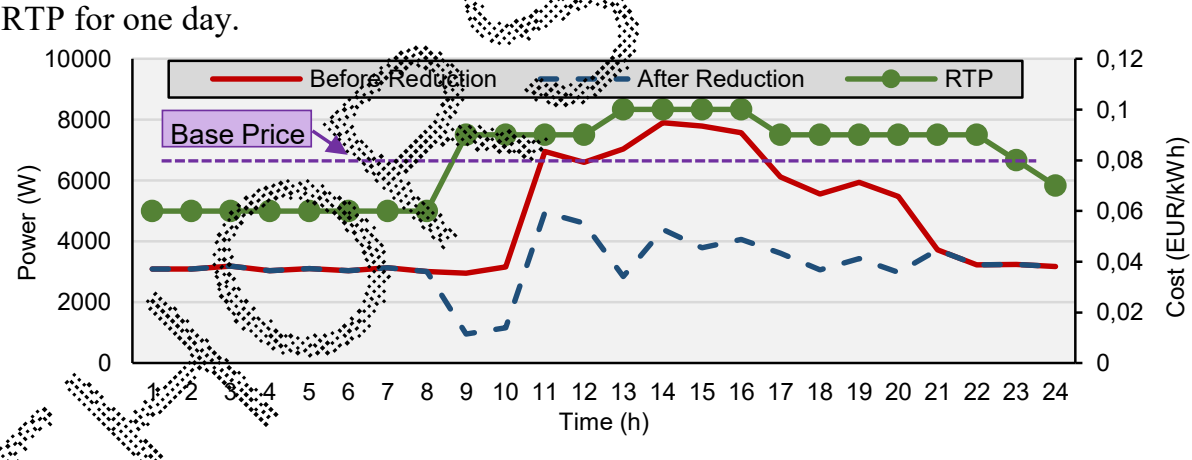

Tig. 4. Consumption reduction in AC devices based on RTP scheme.

The the required reduction of the algorithm and the priority of each devices defined by the users. 获 Fig. 4, and Fig. 5 show, whenever the electricity prices increased and goes above the Base Price, the optimization process reduces the consumption of ACs as much as it can, and some periods that ACs reduction would not fulfill the system goal, the optimization reduce the rest of consumption from the lighting system (period \#13 to \#20 in Fig. 5).

Moreover, as Fig. 4 and Fig. 5 demonstrates, in period \#21 and \#22, even though the electricity price is greater than the Base Price, the optimization is not performed, since 
there was not enough available consumption in order to be reduced. As a last result, Fig. 6 illustrates the effect of optimization in the energy bill of the building for one day.
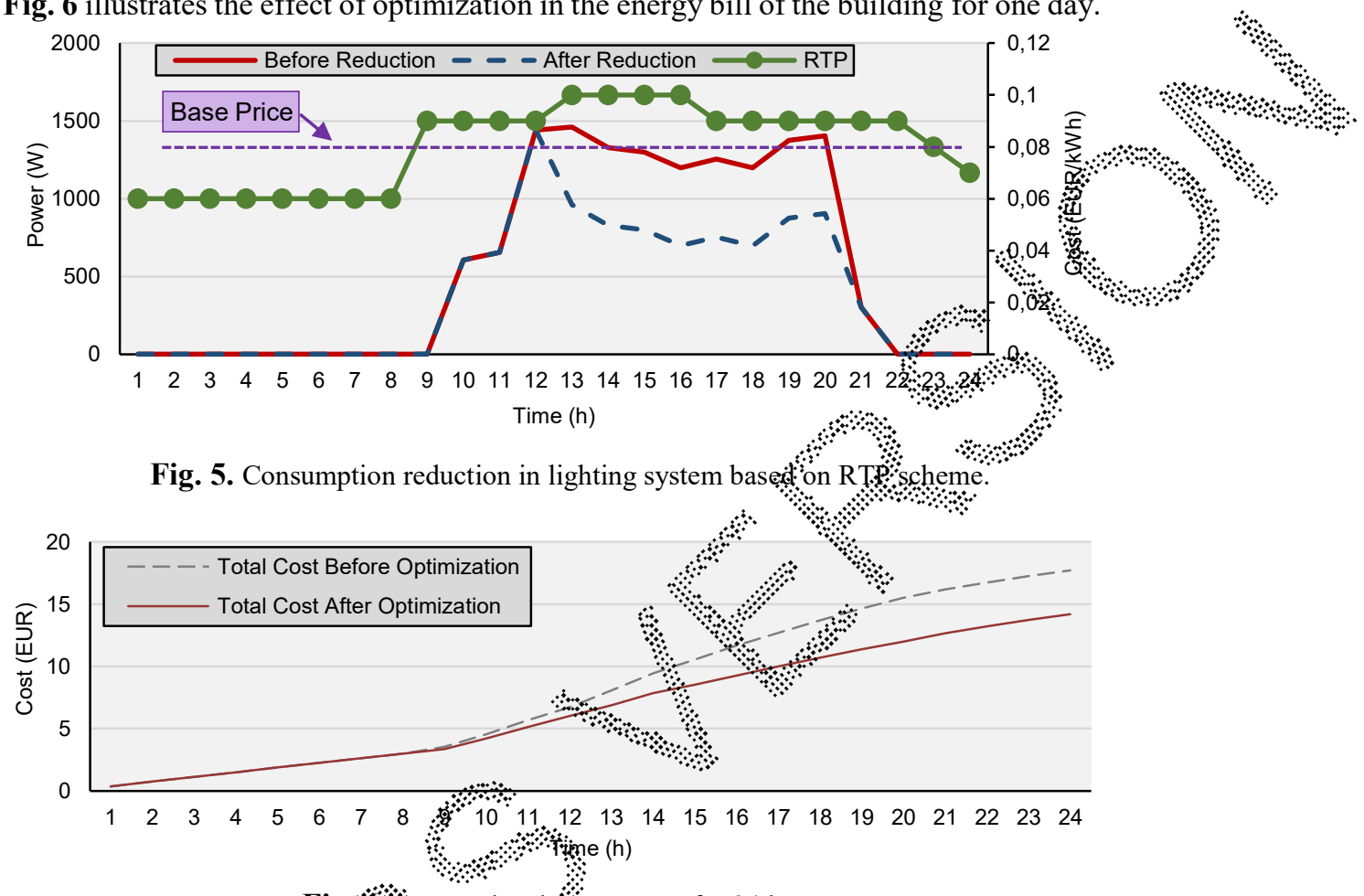

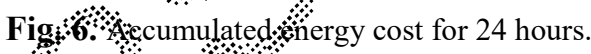

As it can be seen in 1 ig. 6 the optimization process leads to reduce the electricity bill of the building: ences.

\section{Conctusions}<smiles>CCCCC</smiles>

In this paper, an optimization algorithm has been proposed for a multi-agent based SieADA sỳstem. This algorithm considered real-time pricing schemes and optimize the

$\therefore \quad$ consumption of an office building in the periods that electricity price is greater than a

. specifit:value. The main purpose of the paper was to optimize the power consumption and reduce energy bill with take advantages of a multi-agent system. The presented fiodel considered several agents associated with several distributed based controller devices in order to perform decision making locally and communicate with other agents to fulfill the overall system's goal.

The results of case study demonstrated that how the proposed optimization algorithm can reduce the energy bills of an office building via the implemented automation infrastructure and multi-agent system. The amount of cost reduction was for a single day, therefore, if the optimization procedure performed for long-term, the consumer will see 
a significant reduction in the monthly energy bill, while its preferences and comforts did not much affected.

\section{References}

1. Abrishambaf, O., Gomes, L., Faria, P., Vale, Z.: Simulation and control of consumption aijo generation of hardware resources in microgrid real-time digital simulator. In: IEEE He.ES Innovative Smart Grid Technologies Latin America (ISGT LATAM), pp. 799-804.Moñ video, Uruguay (2015).

2. Park, L., Jang, Y., Cho, S., Kim, J.: Residential Demand Response for Renew Enotigle En Resources in Smart Grid Systems. IEEE Transactions on Industrial Informatics 13.6\% 3173 (2017).

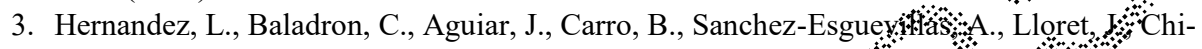
narro, D., Gomez-Sanz, J., Cook, D.: A multi-agent system archijetecture. agement and forecasting of energy demand in virtual power plât. If Magazine 51(1), 106-113 (2013).

4. Foo. Eddy, Y., Gooi, H., Chen, S.: Multi-Agent System for Distaibuted.Management of Mi-

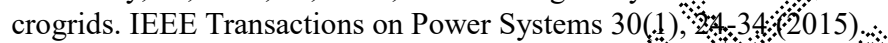

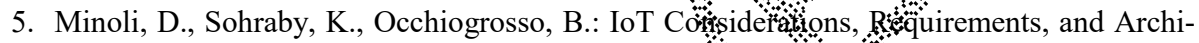
tectures for Smart Buildings - Energy Optimization âtion Nexilding Management Systems. IEEE Internet of Things Jouritut.4.(1), 2017).

6. Esmaeilzadeh, A., Koma, A., Farajollahi, M.: In liphongtation of intelligent methods of building energy management for econsomic optimization. In: IEEE International Conference on Smart Energy Grid Engineerifto (SEGE), pp. 286-293, Oshawa, ON, Canada (2017).

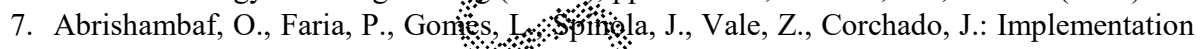
of a Real-Time Microgrid Simulâtron Platfo

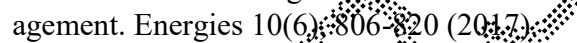

8. Faria, P., Spinola, J., Producers for the Definitigu of Demand-Response Programs. IEEE Transactions on Industrial Informaticsis

9. Faria, P., Vatê Z.: Denịnd response in electrical energy supply: An optimal real time pricing approachi Energy 36\%

10. Tsui, K..Chäa.: S.: Detiond Response Optimization for Smart Home Scheduling Under Real-Timentricing:

11. Fannand For Horais, H., Faria, P., Vale, Z., Ramos, C.: SCADA house intelligent man-

agênt for enêrgy efficiency analysis in domestic consumers. In: IEEE PES Conference

on Inniokative Smart Grid Technologies (ISGT Latin America), pp. 1-8, Sao Paulo, Brazil

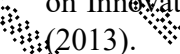

12. Manickavasagam, K.: Intelligent Energy Control Center for Distributed Generators Using Mülti-Agent System. IEEE Transactions on Power Systems 30(5), 2442-2449 (2015).

13. Santos, G., Femandes, F., Pinto, T., Silva, M., Abrishambaf, O., Morais, H., Vale, Z.: House management system with real and virtual resources: Energy efficiency in residential microgrid. In: Global Information Infrastructure and Networking Symposium (GIIS), pp. 1-6, Porto, Portugal (2016).

14. Gazafroudi, A., Pinto, T., Prieto-Castrillo, F., Corchado, J., Abrishambaf, O., Jozi, A., Vale, Z.: Energy flexibility assessment of a multi agent-based smart home energy system. In: IEEE 17th International Conference On Ubiquitous Wireless Broadband (ICUWB), pp. 1-7, Salamanca, Spain (2017). 